\title{
Application Article \\ Low Profile, Dual-Polarised Antenna for Aeronautical and Land Mobile Satcom
}

\author{
Martin Shelley, Robert Pearson, and Javier Vazquez \\ Cobham Technical Services, Cleeve Road, Leatherhead, Surrey KT22 7SA, UK \\ Correspondence should be addressed to Martin Shelley, martin.shelley@cobham.com
}

Received 30 September 2008; Accepted 5 February 2009

Recommended by Stefano Selleri

\begin{abstract}
High data rate communications on the move is fastly becoming a major application area for satellite systems using Ku- and higher frequency bands. The ground terminal antenna used in such systems has a profound impact on the system capabilities and is constrained in many often conflicting ways. While simple reflector systems offer the lowest cost solution, there is a widespread need for low profile antennas to minimize the antenna visual signature and to satisfy aesthetic and transportation requirements. It is often considered that the use of such antennas will compromise the system performance.
\end{abstract}

Copyright ( 12009 Martin Shelley et al. This is an open access article distributed under the Creative Commons Attribution License, which permits unrestricted use, distribution, and reproduction in any medium, provided the original work is properly cited.

\section{Introduction}

In this paper, which is an extended version of a submission presented at the 4th Advanced Satellite Mobile Systems Conference, Bologna, August 26-28, 2008 [1], it will be shown that, in many scenarios, the use of low profile antenna solutions has operational as well as mechanical advantages. The paper will illustrate why this is the case and describe a unique low profile antenna solution that is being developed to make these advantages available to the system designer.

Agencies providing defense and emergency services are increasingly reliant on mobile communications. Travelling rapidly over large areas, mobile units require real-time, agile, communication systems for voice, data, images, and video. Airborne systems must operate in severe environmental conditions and meet demanding certification requirements; land systems must operate during all vehicle maneuvers, and should be unaffected by the type of terrain encountered. Installations on small business jets and UAVs, commercial and military aircraft, and a wide range of land vehicles including HMMWVs and SUVs, have to be very low profile to meet requirements for low drag, easy transportation and small visual signature.

A key requirement for satcom-on-the-move (SOTM) systems is to maximize the data throughput using an antenna with smallest aperture. Section 2 below shows that low profile solutions have to potential to maximize data rates for many operational scenarios combining the clear physical advantages with significant system benefits.

Section 3 describes a new highly robust antenna system which has been developed, suitable for mounting on aeronautical and land vehicles, to capitalize on these benefits.

\section{Benefits and Shortcomings of the Low Profile Antenna Solution}

For any given two-way mobile communications system operating in $\mathrm{Ku}-\mathrm{Band}$, transmit requirements always dominate when sizing the mobile antenna and its associated power amplifier system. The aperture area of the antenna will determine its transmit gain. Regulations [2-5] will then limit the amount of power the user is allowed to radiate (defined in terms of EIRP/bandwidth), based on sidelobe templates defined to limit interference to adjacent satellites. This limit on the operation of the system will depend on the antenna aperture size and shape, and the relative locations of the user, and the satellite and the nearest neighboring satellites. Generally, the limit is only applied along the geostationary arc and antenna performance outside this region is unconstrained. Different operators apply different limits. Figure 1 shows some of the more common regulatory templates. 


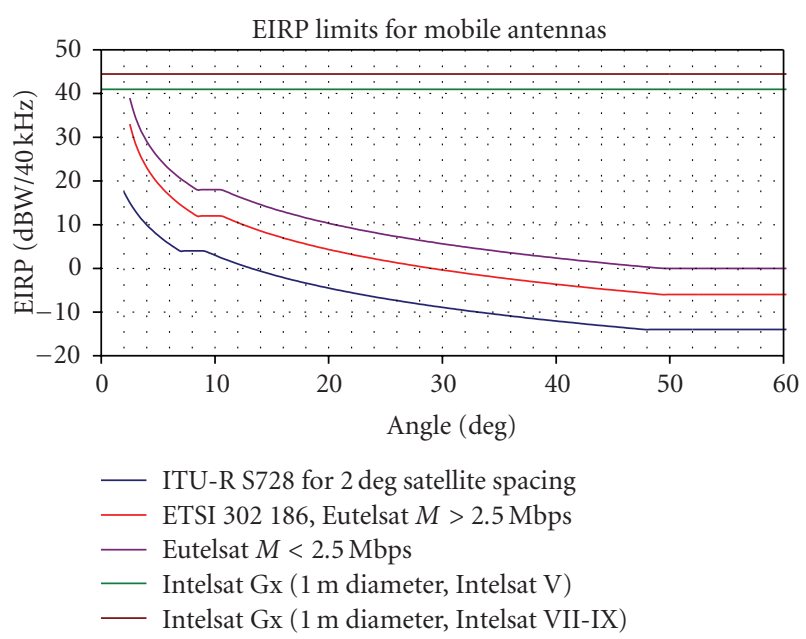

FIGURE 1: Typical transmit system regulatory templates.

Since the templates only apply close to the geostationary arc, a low profile antenna solution can have significant benefits when compared to an equivalent circular reflector in many situations.

Generally, unless the satellite and user have very different longitudes and/or the user is very close to the Equator, a mobile terminal will need to look in a southerly direction (if in the Northern Hemisphere) to form a link with a satellite in the geostationary arc. In this instance, the geostationary arc will be broadly aligned to the azimuth radiation pattern of the antenna, and in order to maximize the power that can be radiated, the antenna needs to have the largest possible aperture dimension in the azimuth plane. For a given aperture area, this is achieved best by using a low profile antenna.

However, if the user is close to the Equator and the satellite has an offset longitude, the geostationary arc is now broadly aligned to the elevation radiation pattern of the mobile antenna. In this instance, the performance of the low profile antenna will be compromised, as the beamwidth will be substantially larger than was previously the case, and the interference potential significantly greater. Taking a typical low profile antenna with a $900 \mathrm{~mm}$ azimuth aperture, Figure 2 shows how the EIRP must be backed off as the beamwidth increases.

An extensive study of this phenomenon has been carried out to assess how it impacts on the EIRP levels that can be radiated for different relative locations of the satellite and mobile. A comparison has been undertaken between the low profile solution, where the performance is location dependent, and a circular reflector with the same gain, where the performance is the same for all locations. A satellite is placed at an arbitrary location of $0 \mathrm{~W}$. The coverage area where the satellite can be accessed is determined, and the beamwidth of the particular mobile antenna in the satellite look direction determined. This is then overlaid on the ITUR S728 template and the maximum EIRP/Hz calculated. This was done for a low profile aperture with dimension

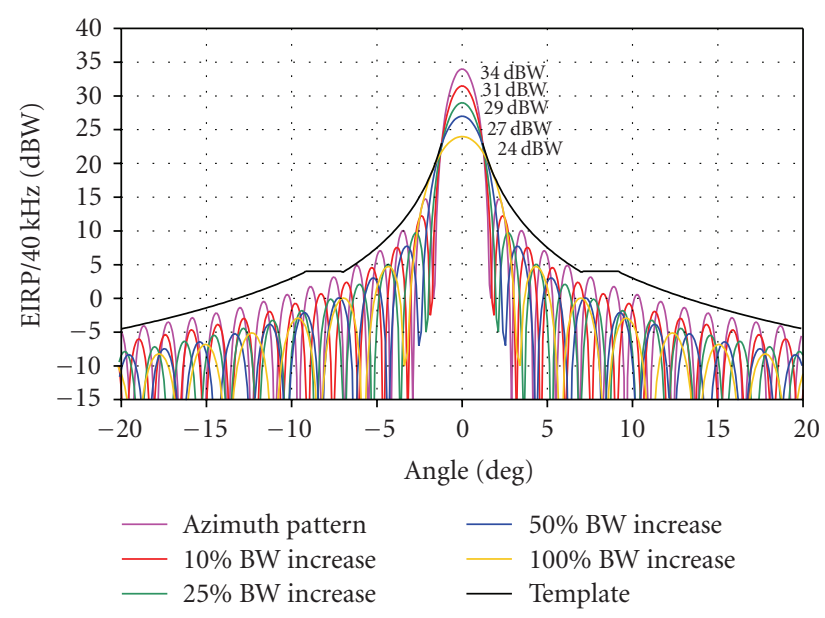

FIGURE 2: Impact of increasing beamwidth on EIRP.

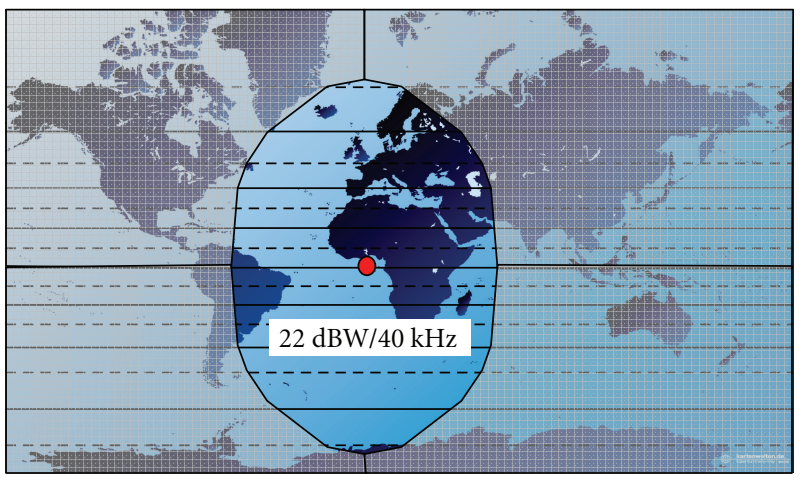

FIGURE 3: EIRP contours for a circular reflector.

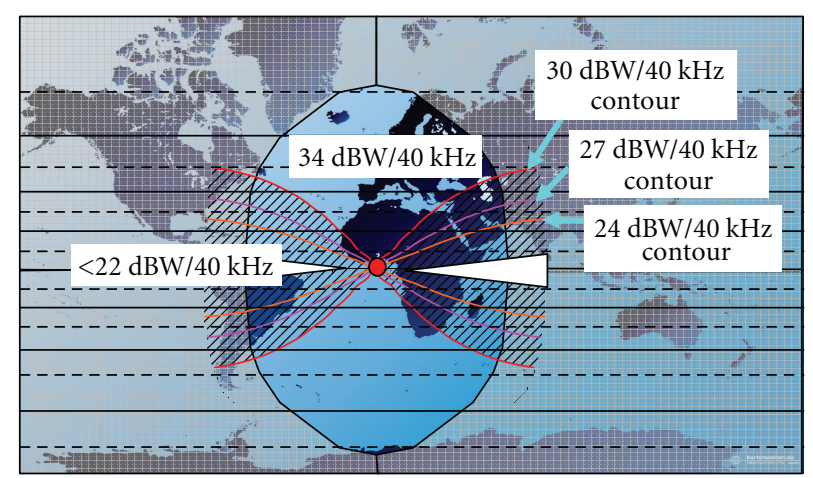

FIgURE 4: EIRP contours for a low profile antenna.

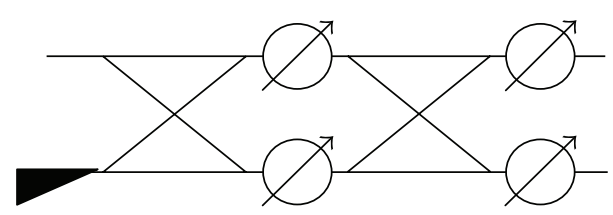

FIGURE 5: Polarisation control network. 


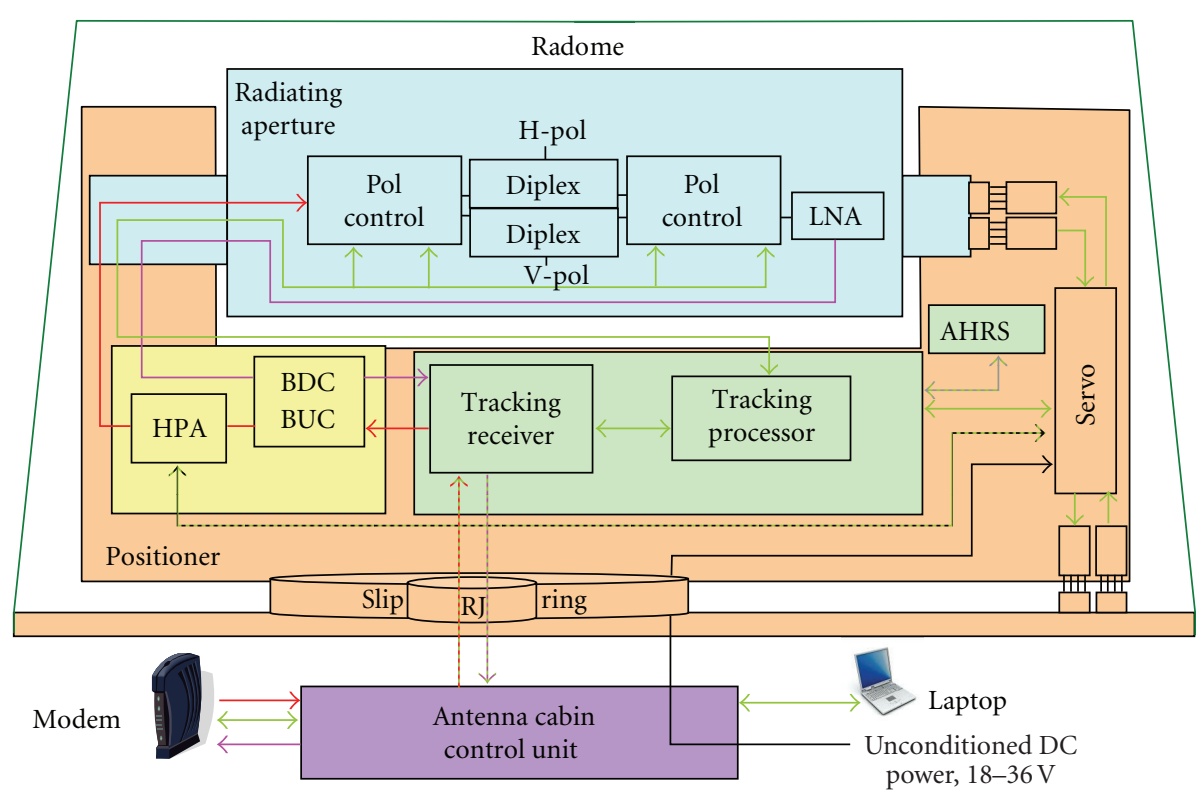

Figure 6: System block diagram.

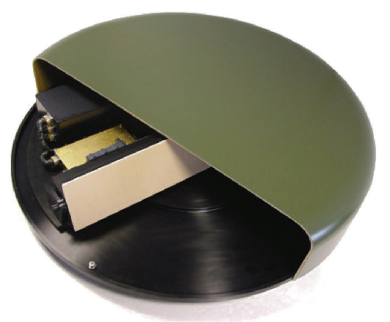

(a)

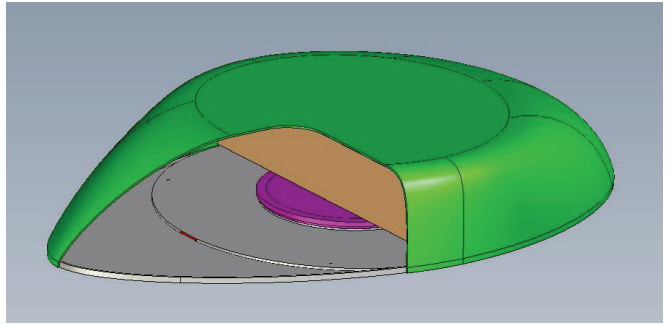

(b)

FIGURE 7: Antenna demonstrato.

$900 \mathrm{~mm} \times 150 \mathrm{~mm}$ and an equivalent $460 \mathrm{~mm}$ diameter circular reflector.

It is found that the low profile solution can provide up to $10 \mathrm{~dB}$ more $\mathrm{EIRP} / \mathrm{Hz}$ (equivalent to a $10 \times$ increase in data rate), over a large percentage of a typical coverage area and that its performance is only degraded with respect to the circular reflector in a small region along the equator at offset longitudes with respect to the satellite. This effect is illustrated in Figures 3 and 4, which shows the EIRP contours for both designs.

\section{Spitfire Low Profile Antenna}

The highly integrated SPITFIRE Ku-Band terminal includes a low profile aperture antenna, a positioner and servo controller, an autonomous tracking receiver, and an internal navigation unit. A low-noise amplifier, block up and down converters, and a high efficiency solid state power amplifier are also included, housed under a common radome above the deck. Key features of the design are

(i) fully integrated antenna terminal, including radome and RF electronics, (ii) designed for commercial air transport and full MIL SPEC off-road applications,

(iii) single, mechanically steered dual-polarised aperture providing a full band RX and TX air interface with zenith to horizon coverage,

(iv) polarisation control function implemented in $\mathrm{Ku}$ Band using unique low-loss components, including compensation for unavoidable radome depolarisation,

(v) integrated onboard INS/GPS, providing low latency position and attitude data,

(vi) simple L-band and power cable interface through the external vehicle skin. All control data sent via RF cables,

(vii) small in-cabin control box, providing direct interface to different modems using RS422 or Ethernet, while also enabling control and monitoring of the system through a laptop computer.

Two versions of the antenna system are offered. The first is suited to the airborne environment, where shock 


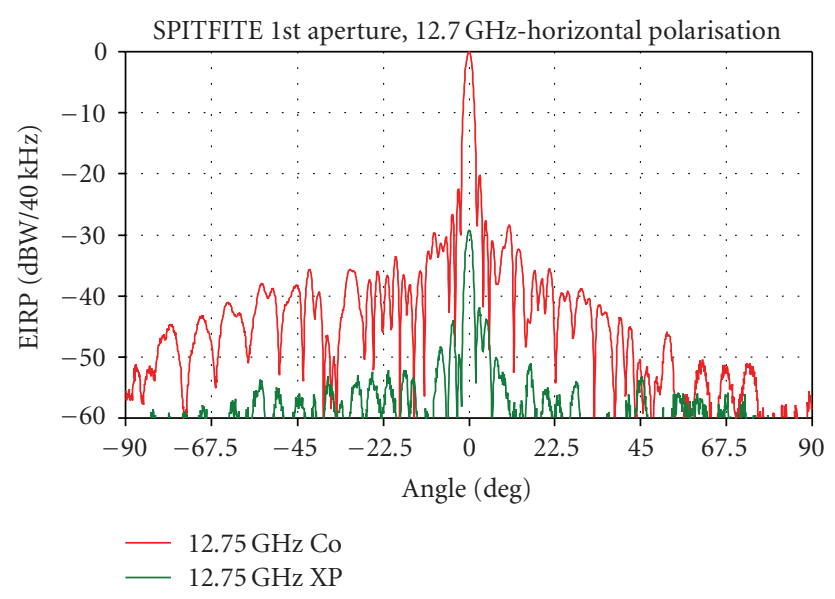

FIGURE 8: Typical measured RX band azimuth radiation pattern.

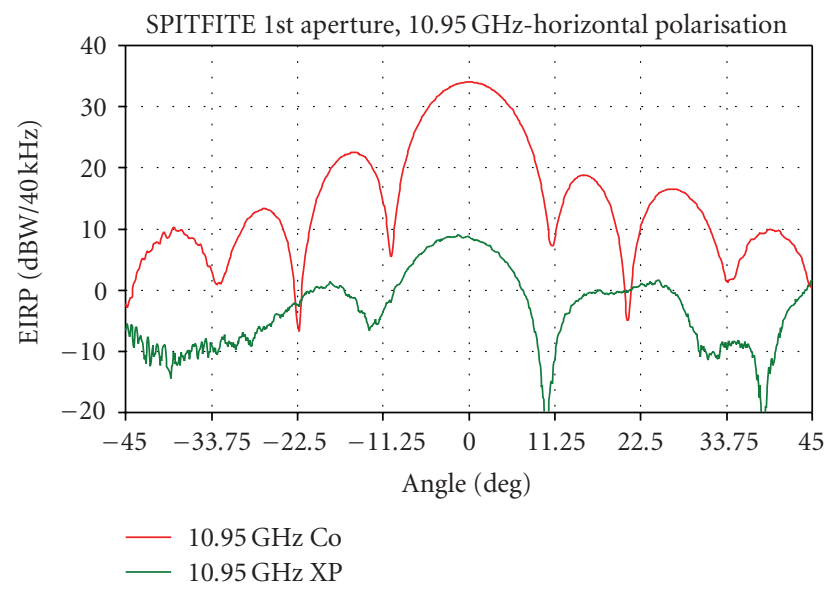

FIgURE 9: Typical measured RX band elevation radiation pattern.

and vibration levels are relatively low and vehicles dynamics benign. The second has a more robust positioner and larger motors which will allow it to operate in the much more demanding off-road scenario, where shock loads are much higher and there is a need to compensate for rapid vehicle attitude changes.

The array aperture is a hybrid construction, combining the benefits of low-loss waveguides with a compact printed circuit implementation where waveguides cannot be accommodated. The radiating elements are compact ridge waveguide horns, matched using an external impedance matching sheet. These are excited using balanced, printed probes formed as part of a stripline elevation power combining structure, configured to give low cross-polarisation. Azimuth beamforming is implemented in waveguide and includes integral diplexers, separating the TX and RX functions.

A waveguide hybrid network is used to control the polarisation, see Figure 5, using unique and patented mechanically adjusted noncontact waveguides [6].

The central phase shifters are adjusted to transfer the input energy between the upper and lower ports of the

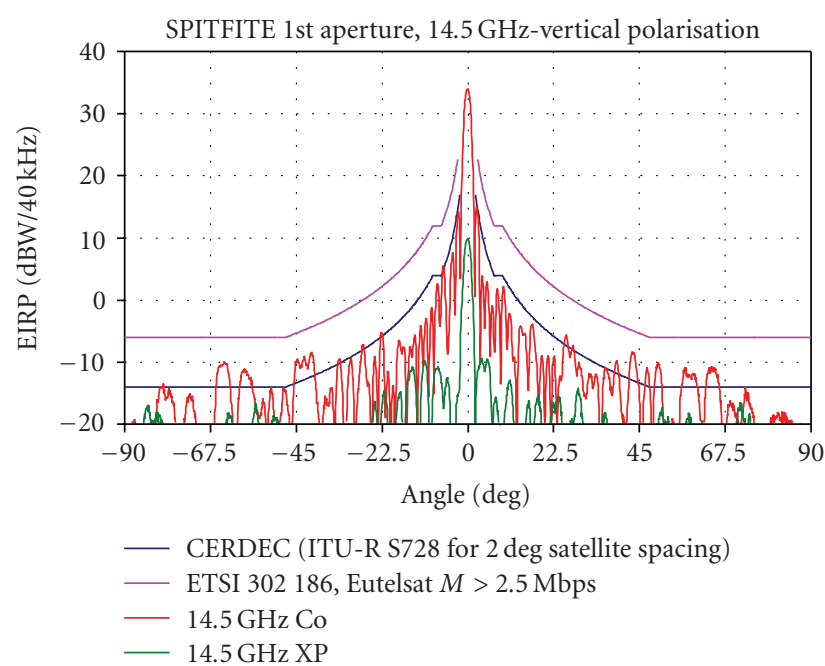

FIgURE 10: Typical measured TX band azimuth radiation pattern.

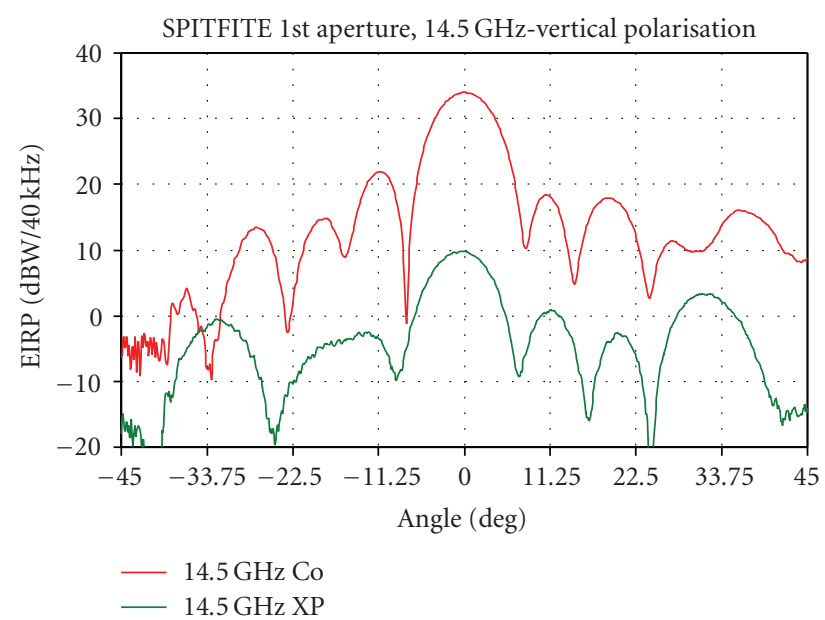

FIGURE 11: Typical measured TX band elevation radiation pattern.

antenna, which are connected to the vertically and horizontally polarised ports on the array face.

Additional phase shifters are provided on each output arm to compensate for radome phase imbalances which are unavoidable at scan angles close to the horizon using a low profile radome. These imbalances can otherwise degrade the cross-polar levels of the complete terminal from better than $-25 \mathrm{~dB}$ to less than $-15 \mathrm{~dB}$.

The antenna system block diagram is shown in Figure 6. The complete antenna, including the land mobile radome, is some $200 \mathrm{~mm}$ tall and has a footprint of $965 \mathrm{~mm}$ diameter. The aeronautical version, with a teardrop radome, has a height of less than $250 \mathrm{~mm}$ and a footprint which is extended in the fore-aft direction to $1600 \mathrm{~m}$, to provide low drag. A photograph of a land mobile version of the antenna, with all the onboard equipment placed on the rotating platform, is shown in Figure 7. A CAD drawing of the aeronautical version, which is nearing completion, is also shown in the figure. 
TABLE 1: Summary of antenna performance.

\begin{tabular}{lcc}
\hline & TX & RX \\
\hline Operating frequency band & $13.75-14.5 \mathrm{GHz}$ & $10.95-12.75 \mathrm{GHz}$ \\
Input return loss & $10 \mathrm{~dB}$ minimum & $10 \mathrm{~dB}$ minimum \\
$\mathrm{G} / \mathrm{T}, 11.7 \mathrm{GHz}$ & - & $10.6 \mathrm{~dB} / \mathrm{K}$ worst case \\
Gain, $14 \mathrm{GHz}$ & $32.2 \mathrm{dBi}$ & - \\
Typical TX EIRP (meeting 25-25 $\log (\theta)$ template) & $34 \mathrm{dBW} / 40 \mathrm{kHz}$ & - \\
Typical data rate capability & $2 \mathrm{Mbps}$ & $20 \mathrm{Mbps}$ \\
Polarisation & Single adjustable Linear & Single adjustable linear, orthogonal to transmit \\
Cross-polarisation on boresight, under all dynamic conditions & $25 \mathrm{~dB}$ worst case & $15 \mathrm{~dB}$ worst case \\
\hline
\end{tabular}

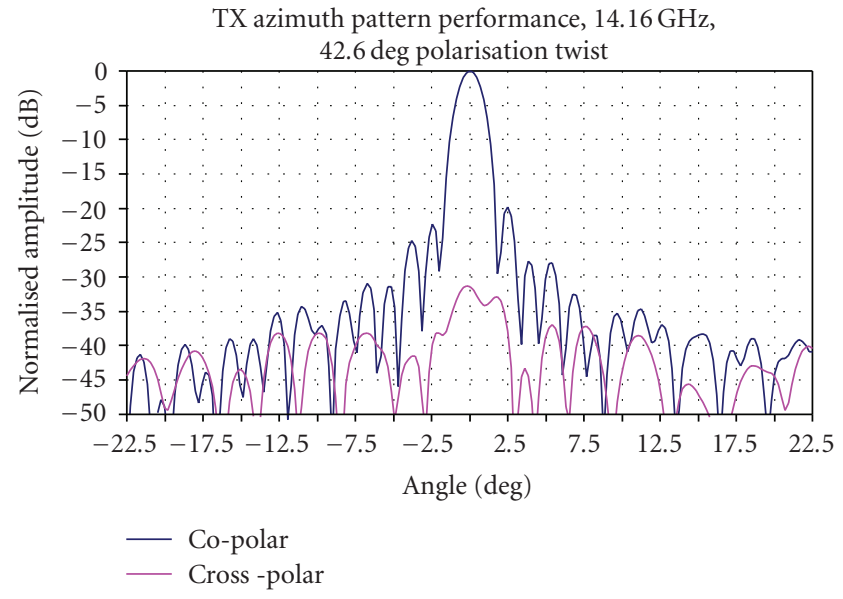

FIGURE 12: TX pattern with $42.6^{\circ}$ polarization.

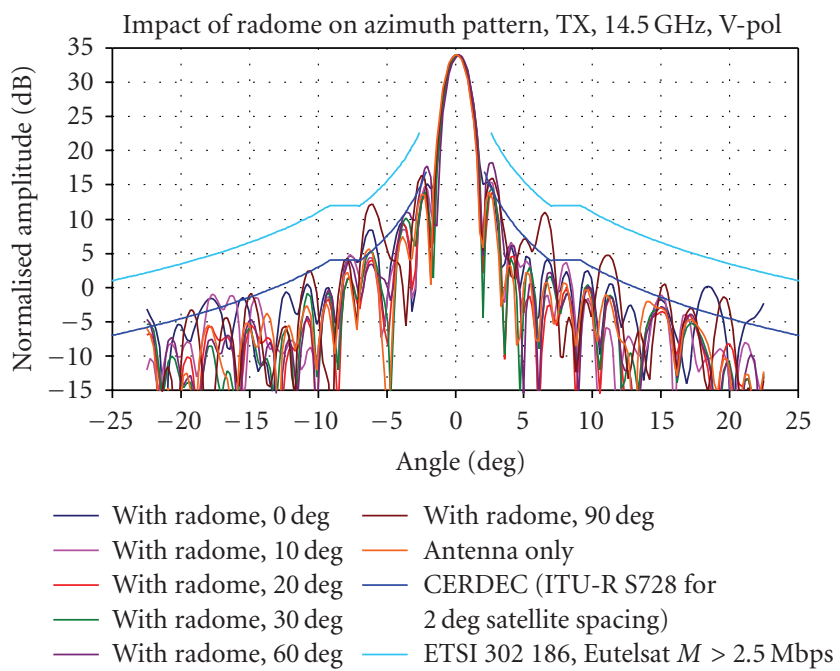

FIgURE 13: Impact of radome on azimuth patterns.

of typically $44 \mathrm{dBW}$ using its internal $20 \mathrm{~W}$ amplifier. Crosspolarisation levels can be maintained below $25 \mathrm{~dB}$ using the polarization control networks.

\section{Conclusions}

In this paper, a key system benefit of using a low profile antenna in place of a circularly symmetrical reflector-based solution has been demonstrated. In most applications, the increased azimuth aperture provides significant additional protection to adjacent satellites and it is therefore possible to use the antenna to radiate much higher power than an equivalent circular reflector and hence makes it possible for a system to operate at a much higher data rate than one using a circular reflector.

The Ku-Band SPITFIRE antenna described allows these benefits to be realized in systems operating in the severe environments encountered onboard aircraft and on the battlefield. The antenna includes a highly integrated high performance aperture coupled to low-loss waveguide-based polarization control mechanisms, eliminating the need for complex electronic phase shifting components. The antenna includes all the tracking and steering components within the radome volume, creating a compact package that can easily be accommodated on a wide range of vehicle platforms. at about $10^{\circ}$ elevation. On the transmit side, the gain is greater than $32 \mathrm{dBi}$, allowing the antenna to radiate an EIRP
A summary of the antenna performance is provided in Table 1 . On the receive side, the G/T is typically better than $11 \mathrm{~dB} / \mathrm{K}$, with a small reduction close to the horizon, where sky noise increases; radome losses are also slightly higher when the antenna looks through the highly curved section

Typical azimuth and elevation radiation patterns of the
erture alone in the TX and RX bands are shown in Figures $8,9,10$, and 11 . These clearly show the excellent pattern and cross-polarization performance that has been achieved. may degrade the antenna performance. The impact of both has been assessed in detail. The antenna has been configured polarization skew of about $45^{\circ}$ is required. Figure 12 shows the TX pattern measured after polarization alignment has The impact of the radome has been assessed by comparing azimuth patterns with and without the radome. Figure 13 control is particularly important. It can be seen that there is minimal degradation at all elevation angles, with some and at zenith (due to direct reflections from the radome urface). 
The tracking and steering solution has been developed to support a range of other radiating apertures, including $\mathrm{X}$ Band, Ka-Band, and Q-Band units and could be used in next generation systems employing multiband apertures.

\section{Acknowledgments}

The authors would like to acknowledge the support which has been given to the development of the SPITFIRE antenna system by the European Space Agency under its ARTES 4 program [7] and by Cobham PLC under its IRAD program. This paper is an extended version of a submission presented at the 4th Advanced Satellite Mobile Systems Conference in Bologna, August 26-28, 2008.

\section{References}

[1] M. W. Shelley, R. A. Pearson, and J. Vasquez, "Low profile, dual polarised antenna for aeronautical and land mobile satcom," in Proceedings of the 4th Advanced Satellite Mobile Systems Conference (ASMS '08), pp. 16-19, ERA Technology Ltd, Bologna, Italy, August 2008.

[2] "RECOMMENDATION ITU-R S.728-1 Maximum permissible level of off-axis e.i.r.p. density from very small aperture terminals (VSATs)," International Telecommunications Union, October 1995.

[3] ETSI 302186 v1.1.1, "Satellite Earth Stations and Systems (SES); Harmonized EN for satellite mobile Aircraft Earth Stations (AESs) operating in the $11 / 12 / 14 \mathrm{GHz}$ frequency bands covering essential requirements under article 3.2 of the R\&TTE Directive," European Telecommunications Standards Institute, April 2004.

[4] EESS 502 Issue 10 - Rev. 0, STANDARD M, "Minimum Technical and Operational Requirements for Earth Stations transmitting to a Eutelsat Transponder for Non-Standard Structured Types of SMS Transmissions," EUTELSAT SA, August 2006.

[5] IESS-601 Rev 12. Standard G., "Performance Characteristics for Earth Stations accessing the Intelsat Space Segment for international and domestic services not covered by other Earth Station Standards," Intelsat, March 2005.

[6] Waveguide, "Sanchez Fransisco Javier Vazquez; Pearson Robert A [GB]," ERA Patents Ltd, Patent no. WO03065497.

[7] "Compact Ku-Band aeronautical antenna for commercial airliners,” ESA Contract 20325/06/NL/US, http://telecom.esa. int/telecom/www/object/index. .cfm?fobjectid=28078. 

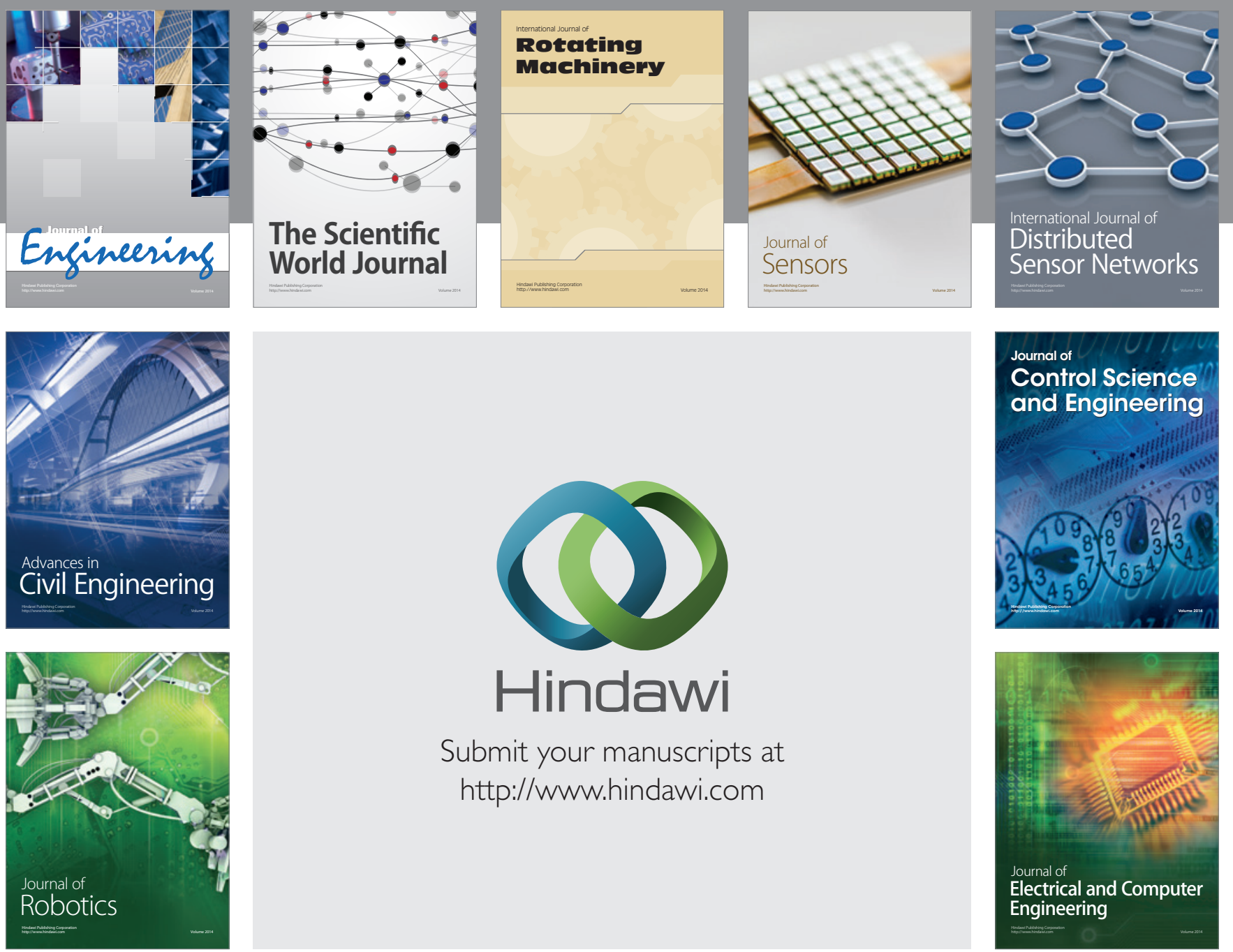

Submit your manuscripts at

http://www.hindawi.com
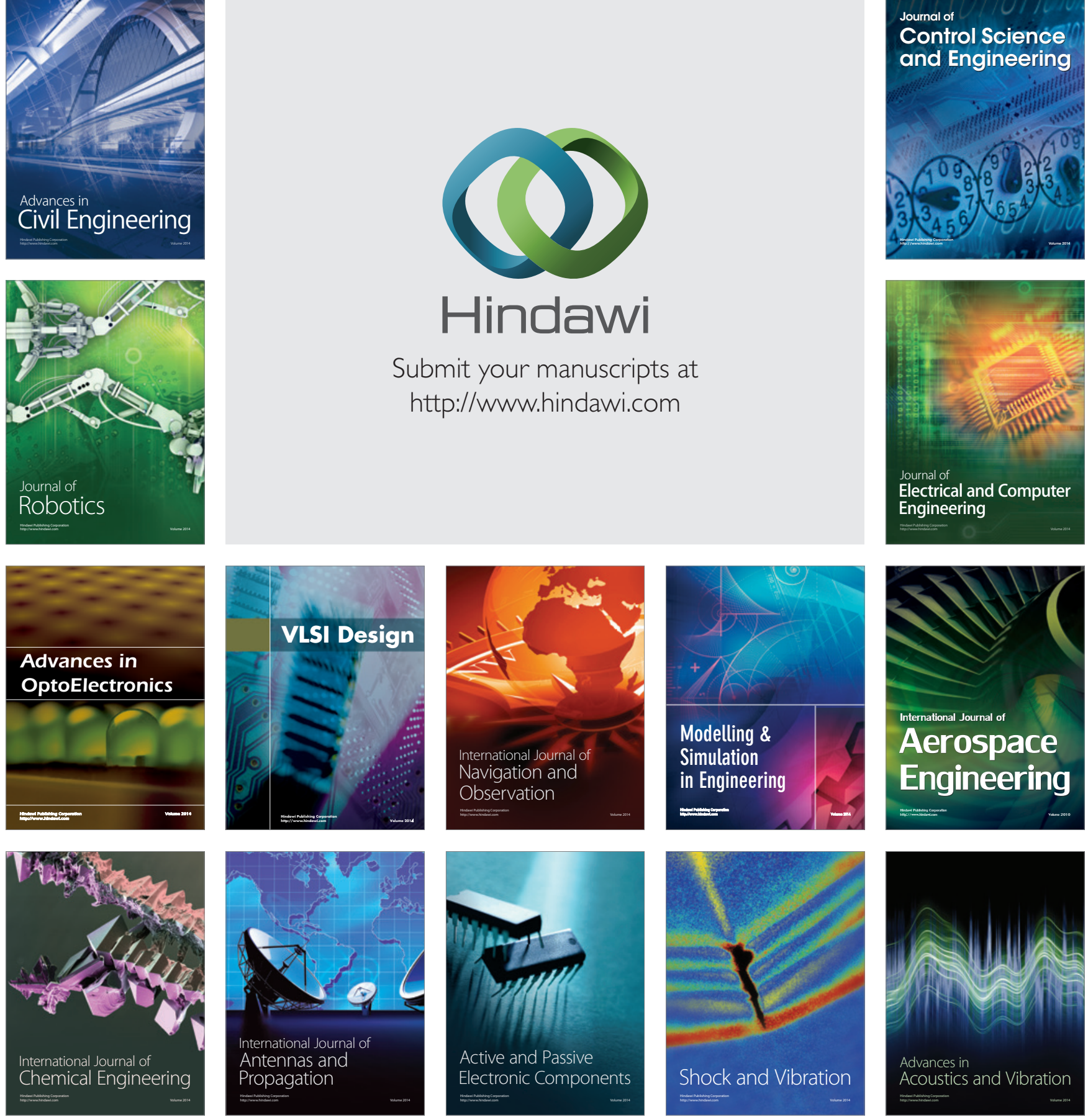